\title{
Dispersion and aggregation of single-walled carbon nanotubes in aqueous solutions of anionic surfactants"
}

\author{
Kun YANG ${ }^{\dagger 1,2}$, Zi-li YI ${ }^{1,2}$, Qing-feng JING ${ }^{1,2}$, Dao-hui LIN ${ }^{1,2}$ \\ $\left({ }^{1}\right.$ Department of Environmental Science, Zhejiang University, Hangzhou 310058, China) \\ ( ${ }^{2}$ Zhejiang Provincial Key Laboratory of Organic Pollution Process and Control, Hangzhou 310058, China) \\ ${ }^{\dagger}$ E-mail: kyang@zju.edu.cn \\ Received Apr. 30, 2014; Revision accepted June 29, 2014; Crosschecked July 18, 2014
}

\begin{abstract}
Understanding the dispersion and aggregation of carbon nanotubes (CNTs) in the aqueous environment are critical for the fate, bioavailability, and the environment and health risk assessment of them because the better suspended CNTs display a higher mobility and could transfer to a longer distance in the environment to possibly pose greater ecological and environmental risks. In this study, we have found that bulk single-walled carbon nanotubes (SWCNTs) could not be dispersed and stably suspended in water and sodium dodecylbenzene sulfonate (SDBS) solution by shaking at $140 \mathrm{r} / \mathrm{min}$, although they could be stably suspended in SDBS solution by sonication. Even through sonication, SWCNTs suspended in SDBS solution do not remain stable at the presence of environmentally relevant cations (e.g., $\mathrm{Na}^{+}, \mathrm{K}^{+}, \mathrm{Ca}^{2+}$, and $\mathrm{Mg}^{2+}$ ) after dilution. These observations suggest that SWCNTs will not travel long distances in significant concentrations in the natural environment to pose great ecological and environmental risks. We also observed that the re-aggregation of suspended SWCNTs in the presence of cations was dependent on the SDBS concentration rather than the SWCNT concentration in the suspension. Both SDBS and sonication play important roles in the dispersion of SWCNTs, with sonication breaking down large aggregates of SWCNTs, while SDBS adsorbed on the SWCNTs inhibits the coagulation and aggregation by steric/electrostatic repulsion to maintain the stability of the suspension in water.
\end{abstract}

Key words: Dispersion, Aggregation, Single-walled carbon nanotubes (SWCNTs), Anionic surfactant, Sonication doi: 10.1631 jzus.A1400113

Document code: A

CLC number: X52

\section{Introduction}

Carbon nanotubes (CNTs), including singlewalled CNTs (SWCNTs) and multi-walled CNTs (MWCNTs), have unique and tunable physical and chemical properties that can be exploited in numerous potential applications. However, CNTs have also attracted notoriety for their possible environmental and health effects (Dunphy Guzmán et al., 2006), as they inevitably enter the environment during their

\footnotetext{
* Project supported by the National Natural Science Foundation of China (Nos. 21322702, 21137003, and 41273125), the National Science \& Technology Pillar Program of China (No. 2013BAC01B01), the Zhejiang Provincial Natural Science Foundation of China (No. R5110004), and the Fundamental Research Funds for the Central Universities (No. 2014XZZX003-30), China

(C) Zhejiang University and Springer-Verlag Berlin Heidelberg 2014
}

production, transport, handling, use, and disposal (Gottschalk and Nowack, 2011), where they can potentially cause damage to aquatic organisms (Cheng et al., 2007), mammals (Lam et al., 2004), and human cells (Jia et al., 2005). The dispersion and aggregation of CNTs in the aqueous environment are critical behaviors affecting their fate, bioavailability, and potential environmental and health risks (Hyung and Kim, 2008; Saleh et al., 2008); more stably suspended CNTs exhibit a higher mobility and could thus be transported longer distances in the environment, thus posing greater ecological and environmental risks (Hyung and Kim, 2008; Bouchard et al., 2012). Both bulk CNTs and stably suspended CNTs are used in industrial applications and can be released into the natural environment (Dunphy Guzmán et al., 2006). Bulk CNTs are generally aggregated in bundles and 
cannot be dispersed significantly in water or even in organic solvents, owing to the strong van der Waals $(\mathrm{vdW})$ interactions along their primary axes (Islam et al., 2003). Surfactants are widely employed as dispersion detergents to prepare stably suspended CNTs for industrial applications (Islam et al., 2003; Zhang et al., 2004; Lin et al., 2009; 2010). Therefore, for a better understanding of the mobility of CNTs in the environment, it is important to examine (1) whether bulk CNTs can be dispersed and stably suspended in the natural environment (Hyung and Kim, 2008; Lin and Xing, 2008) and (2) whether surfactant-suspended CNTs can retain their stability in the natural environment (Saleh et al., 2008).

It has been widely reported that bulk CNTs can be dispersed and stably suspended in aqueous solutions of surfactants and natural organic matter (NOM) using sonication (Hyung and Kim, 2008; Lin et al., 2009; 2010). Surfactants and NOM are surface active and ubiquitous in the environment. Surfactants are mainly used in households and in industry as detergent formulations and surface cleaners and are discharged into the environment in huge quantities (Matthijs et al., 1999). They are synthesized by bacteria, yeasts, and fungi in the environment (Zajic et al. 1983). NOM is a key component of soils, sediments, and natural water and which originates primarily from the biological degradation of plants as well as animal remains (McRae, 1988). Sonication is a method of vigorously agitating water and is an important process for dispersing or debundling CNT aggregates and bundles (Islam et al., 2003). However, sonication induces more extreme agitation than is encountered in the natural aqueous environment. Therefore, the results of experiments using vigorous sonication are not appropriate for assessing and predicting the dispersion and suspension of bulk CNTs in the aqueous environment. For example, MWCNTs can be dispersed and stably suspended in natural surface water containing dissolved NOM by sonication but not by shaking at $140 \mathrm{r} / \mathrm{min}$ (Lin et al., 2010); the latter represents realistic agitation conditions encountered in the natural aqueous environment and is widely used in experiments on the sorption of contaminants by CNTs, sediments, and soils (Yang et al., 2006). Therefore, milder methods, such as shaking, should be employed in experiments on the dispersion and suspension of bulk CNTs in aqueous solutions of surfactants and NOM (Lin and Xing, 2008; Lin et al., 2010).
The effect of cations including $\mathrm{Na}^{+}, \mathrm{K}^{+}, \mathrm{Mg}^{2+}$, and $\mathrm{Ca}^{2+}$ on the aggregation and deposition of stably suspended CNTs has been widely studied, because these electrolyte ions are ubiquitous in the aqueous environment and are known to coagulate certain colloidal sols (Saleh et al., 2008; Lin et al., 2010; Bouchard et al., 2012). Previous studies have reported that these cations could coagulate and deposit stably suspended CNTs by depressing the electric double layer (Saleh et al., 2008). A certain minimum concentration of a given electrolyte ion is needed to induce the diffusion-limited aggregation of CNTs; this concentration is commonly referred to as the critical coagulation concentration (CCC) (Bouchard et al., 2012). Most reported CCC values (Saleh et al., 2008; 2010; Lin et al., 2010; Bouchard et al., 2012) for $\mathrm{Na}^{+}$, $\mathrm{K}^{+}, \mathrm{Mg}^{2+}$, and $\mathrm{Ca}^{2+}$, although dependent on the physicochemical properties of the CNTs (e.g., surface oxygen-containing functional groups (Smith et al., 2009)) and solution chemistry (e.g., dispersant types (Saleh et al., 2008; 2010; Lin et al., 2010)), were higher than their average concentrations in fresh river water (i.e., $0.22,0.034,0.16$, and $0.36 \mathrm{mmol} / \mathrm{kg}$ (Broecker et al., 1982), respectively) but lower than that in surface seawater (i.e., 470, 10.2, 53, and $10.3 \mathrm{mmol} / \mathrm{kg}$ (Broecker et al., 1982), respectively). These findings suggest that stably suspended CNTs can remain stable and be transported long distances in the natural terrestrial ecosystem, and thus pose an unexpected degree of ecological and environmental risk. However, these findings were mostly obtained from experiments that employed higher concentrations of CNTs as well as dispersion detergents (e.g., surfactants and NOM) typical of industrial applications rather than those found in the environment. For example, the reported concentration of the surfactant sodium dodecylsulfate (SDS) for stabilizing CNTs was up to $20000 \mathrm{mg} / \mathrm{L}$ (Islam et al., 2003). The dilution of a stable suspension of CNTs to lower concentrations of dispersion detergents and suspended CNTs occurs as soon as the industrial suspension is released into the surface or ground waters; this phenomenon has not previously been considered in studies on the environmental fate and transport of CNTs. Bouchard et al. (2012), investigating the effects of lower surfactant concentrations (SDS 5-500 mg/L) on the CNTs dispersibility, observed that the CCC values increased with the SDS concentration for $\mathrm{Na}^{+}$but were almost independent of the SDS concentration 
for $\mathrm{Ca}^{2+}$. Therefore, to estimate environmental exposure, the dependence of $\mathrm{CCC}$ values on the concentration of CNTs and dispersion of detergents must be investigated with respect to their environmental distribution, fate, and transport.

Therefore, experiments were conducted on the dispersion of bulk SWCNTs in aqueous solutions of an anionic surfactant (sodium dodecylbenzene sulfonate (SDBS)), with and without the use of sonication, to investigate whether shaking at $140 \mathrm{r} / \mathrm{min}$ alone, a mild agitation representative of the natural aqueous environment, could cause bulk SWCNTs to be dispersed and stably suspended in the SDBS solution. The effects of environmentally relevant cations, including monovalent (i.e., $\mathrm{Na}^{+}$and $\mathrm{K}^{+}$) and divalent (i.e., $\mathrm{Ca}^{2+}$ and $\mathrm{Mg}^{2+}$ ) ions, and the concentrations of SWCNTs and SDBS on the aggregation (i.e., CCC values) of SDBS-suspended SWCNTs were also investigated to determine whether SDBS-suspended SWCNTs can retain their stability when a stable suspension of CNTs is diluted to lower concentrations. This information will be helpful in estimating the environmental distribution, fate, and transport of CNTs and, thus, the environmental exposure risks.

\section{Materials and methods}

\subsection{Materials}

SDBS was obtained from the Tokyo Chemical Industry Co., Ltd., and used as purchased as the dispersion detergent. The purity and critical micelle concentration (CMC) of SDBS was $98 \%$ and $963 \mathrm{mg} / \mathrm{L}$, respectively (Yang et al., 2007). SWCNTs, with a purity of $90 \%$, outer diameter of 1-2 nm, and specific surface area of $385 \mathrm{~m}^{2} / \mathrm{g}$, were purchased from the Chengdu Organic Chemistry Ltd., and used in the experiments as received. The specific surface area of the SWCNTs was calculated from the $\mathrm{N}_{2}$ adsorption isotherm using the multi-point BrunauerEmmett-Teller method. The $\mathrm{N}_{2}$ adsorption isotherm of the SWCNTs was obtained at $77 \mathrm{~K}$ (Autosorb-1, Quantachrome) after outgassing at $105{ }^{\circ} \mathrm{C}$ for at least $24 \mathrm{~h}$.

\subsection{Dispersion and adsorption experiments}

SWCNTs $(8,40$, or $150 \mathrm{mg})$ were added to $20 \mathrm{ml}$ vials along with $20 \mathrm{ml}$ of SDBS solution with initial concentrations of up to $8000 \mathrm{mg} / \mathrm{L}$ at neutral $\mathrm{pH}$. The vials were sealed with aluminum-foil-lined Teflon screw caps and sonicated in a bath sonicator (KQ-600KDE, Shumei, China) at a fixed frequency of $40 \mathrm{kHz}$ for $11 \mathrm{~h}$ at $(25 \pm 5){ }^{\circ} \mathrm{C}$ or shaken at $140 \mathrm{r} / \mathrm{min}$ for $2 \mathrm{~d}$ at $(25 \pm 1)^{\circ} \mathrm{C}$. Preliminary experiments indicated that the apparent equilibrium of both the dispersion of the SWCNTs and the adsorption of SDBS on the SWCNTs was reached after sonication for $11 \mathrm{~h}$ or shaking for $2 \mathrm{~d}$. After equilibration, the mixtures in the vials were centrifuged at $3000 \mathrm{~g}$ for $70 \mathrm{~min}$ to obtain stable SWCNT suspensions. In previous studies (Lin and Xing, 2008; Bai et al., 2010; Lin et al., 2010), centrifugation was observed to be a more suitable method of obtaining stable suspensions of CNTs compared with settling for $4 \mathrm{~d}$ (Hyung et al., 2007; Hyung and Kim, 2008). The stable suspensions of SWCNTs were measured directly with a UV-vis spectrometer (UV-2450, Shimadzu) at $800 \mathrm{~nm}$ to quantify the concentrations of SWCNTs in the suspensions (Hyung et al., 2007; Hyung and Kim, 2008) based on that (1) a linear relationship between the absorbance at $800 \mathrm{~nm}$ and the CNT concentration was observed in previous studies (Lin and Xing, 2008; Bai et al., 2010; Lin et al., 2010) and in the preliminary experiments of this study, and (2) the SDBS solution was found to exhibit no absorbance at $800 \mathrm{~nm}$ in this study. The concentrations of SDBS in the suspensions were also quantified with the UV-vis spectrometer but at $260 \mathrm{~nm}$ and after the suspensions were filtered through $0.2-\mu \mathrm{m}$ poly (tetrafluoroethylene) filters (Millipore). According to previous observations (Lin and Xing, 2008; Bai et al., 2010; Lin et al., 2010), the filter is effective in removing the suspended SWCNTs. The amount of SDBS adsorbed on the SWCNTs was thus calculated from the mass difference between the SDBS in the initial solution and in the suspension.

\subsection{Aggregation experiments}

SWCNTs (400 mg) in $1 \mathrm{~L}$ of SDBS solution with a concentration of $5000 \mathrm{mg} / \mathrm{L}$ at neutral $\mathrm{pH}$ were sonicated at a fixed frequency of $40 \mathrm{kHz}$ for $11 \mathrm{~h}$, followed by centrifugation at $3000 \mathrm{~g}$ for $70 \mathrm{~min}$ to obtain a stable suspension to serve as the stock SWCNT suspension for the aggregation experiments. This was diluted to four concentrations (the SDBS concentrations in the diluted suspension were 50, 500, 1000 , or $2500 \mathrm{mg} / \mathrm{L}$ ) in $20-\mathrm{ml}$ vials using $\mathrm{Na}^{+}, \mathrm{K}^{+}$, 
$\mathrm{Ca}^{2+}$, or $\mathrm{Mg}^{2+}$ solutions (made from their chloride salts) with various ion concentrations at neutral $\mathrm{pH}$. Then, the mixtures were shaken at $140 \mathrm{r} / \mathrm{min}$ at $(25 \pm 1){ }^{\circ} \mathrm{C}$ for $24 \mathrm{~h}$ and subsequently centrifuged at $3000 \mathrm{~g}$ for $70 \mathrm{~min}$ to yield the stable suspensions of SWCNTs; the SWCNT concentrations were then quantified at a UV wavelength of $800 \mathrm{~nm}$. Stable SWCNT suspensions containing $500 \mathrm{mg} / \mathrm{L}$ SDBS and $3.7,5.6,7.0$, or $9.2 \mathrm{mg} / \mathrm{L}$ SWCNTs were also prepared through dilution of the stock SWCNT suspension with $\mathrm{Ca}^{2+}$ solution at various concentrations to examine the effect of SWCNT concentration on its aggregation by $\mathrm{Ca}^{2+}$.

\subsection{Characteristics of SWCNT suspension}

Zeta potential measurements of SWCNT suspensions were performed on a Zetasizer (ZEN 3690, Malvern). Electron microscopic images of SWCNTs were obtained using an FEI F20 transmission electron microscope (TEM) at $200 \mathrm{kV}$. A droplet of the diluted SWCNT suspension was air-dried onto a 300-mesh copper grid (T11012, Beijing XXBR Technology Co., Ltd.) for $2 \mathrm{~h}$ before observation.

\section{Results and discussion}

\subsection{Dispersion of bulk SWCNTs in SDBS solution}

Fig. 1 shows that, with sonication, SWCNTs can be dispersed and stably suspended in the SDBS solution. The amounts of both the stably suspended SWCNTs $(Q)$ and the adsorbed SDBS on SWCNTs $(q)$ increased with the equilibrium SDBS concentration $\left(C_{\mathrm{e}}\right)$ to reach asymptotic values of $3500 \mathrm{mg} / \mathrm{L}$ and $250 \mathrm{mg} / \mathrm{g}$, respectively, at the equilibrium SDBS concentration of approximately $2500 \mathrm{mg} / \mathrm{L}$ (Fig. 1). The addition of more SWCNTs resulted in more SWCNTs being dispersed and stably suspended (Figs. 1 and 2). All three suspension curves for the added SWCNT doses of 400, 2000, and $7500 \mathrm{mg} / \mathrm{L}$ showed similar trends, with the adsorption isotherm of SDBS reaching its asymptotic value at an equilibrium SDBS concentration of around $2500 \mathrm{mg} / \mathrm{L}$. The plateau values of the concentration of stably suspended SWCNTs at doses of 400, 2000, and $7500 \mathrm{mg} / \mathrm{L}$ were approximately half the dose, i.e., 200 , 1000 , and $3500 \mathrm{mg} / \mathrm{L}$, respectively (Figs. 1 and 2). The amount of stably suspended SWCNTs increased with the amount of SDBS adsorbed on the SWCNTs (Fig. 3), indicating that the adsorption of SDBS plays an important role in the dispersion of SWCNTs. However, only shaking at $140 \mathrm{r} / \mathrm{min}$, SWCNTs cannot be stably suspended in SDBS solution, even when the SDBS concentration and the amount of adsorbed

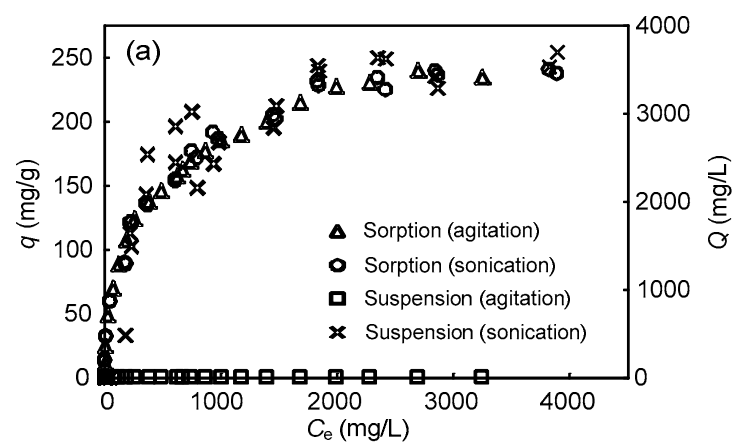

(b) Sonication Shaking

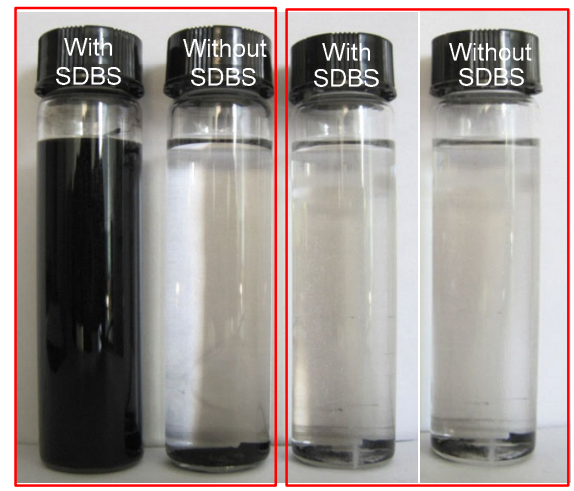

Fig. 1 Amounts of stably suspended SWCNTs and adsorbed SDBS on SWCNTs versus the equilibrium SDBS concentration after the SWCNTs (with an initial dose of $7500 \mathrm{mg} / \mathrm{L}$ in solution) sonicated for $11 \mathrm{~h}$ or shaken for $2 \mathrm{~d}$ (a) and images of the dispersion of SWCNTs in 0 and $5000 \mathrm{mg} / \mathrm{L}$ SDBS solutions after sonication and shaking (b)

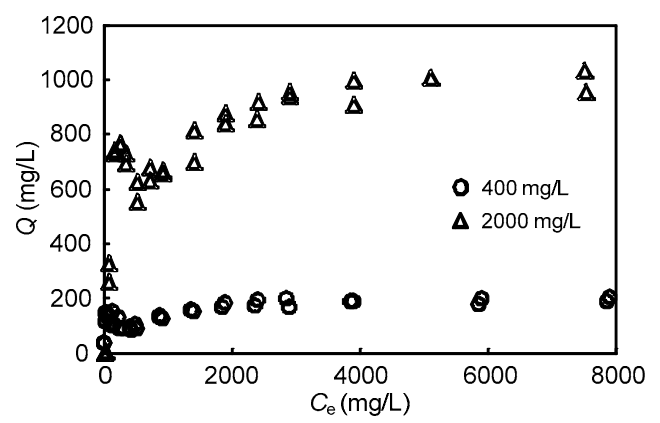

Fig. 2 Amounts of stably suspended SWCNTs at the SWCNT doses of 400 and $2000 \mathrm{mg} / \mathrm{L}$ versus the equilibrium SDBS concentration after sonication for $11 \mathrm{~h}$ 


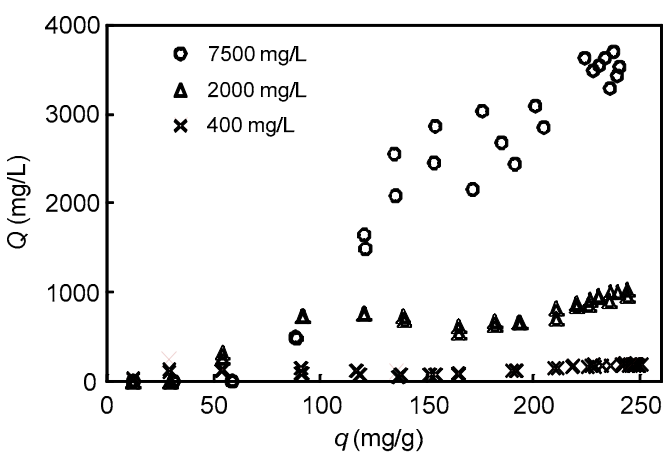

Fig. 3 Amounts of stably suspended SWCNTs at three doses of SWCNTs (i.e., 400, 2000, and $7500 \mathrm{mg} / \mathrm{L}$ ) versus the amount of SDBS adsorbed on the SWCNTs

SDBS were up to $5000 \mathrm{mg} / \mathrm{L}$ and $250 \mathrm{mg} / \mathrm{g}$ (i.e., the plateau value of adsorbed SDBS), respectively (Fig. 1). However, the adsorption isotherm of SDBS on the SWCNTs after sonication at $40 \mathrm{kHz}$ for $11 \mathrm{~h}$ overlaps with that after shaking at $140 \mathrm{r} / \mathrm{min}$ for $2 \mathrm{~d}$ (Fig. 1). These findings indicate that (1) sonication plays an important role in the dispersion of SWCNTs in SDBS solution and (2) bulk SWCNTs cannot be dispersed, stably suspended, or transported long distances at significant concentrations in the environment, even when mixed with ubiquitous surfactants and NOM after being released into the environment; this is because mild shaking at $140 \mathrm{r} / \mathrm{min}$ is reflective of the natural aqueous environment, whereas extreme agitation by sonication is not.

Suspension of CNTs in surfactant solutions with the assistance of sonication has been explained by the "Unzippering" theory postulated by Strano et al. (2003) or alternatively by the "Cutting" theory of Liu et al. (1998). The "Unzippering" theory suggests that gaps or spaces can be created at bundle ends of CNTs in the high-shear environment of the sonicated solution, and then surfactant adsorption and diffusion can enlarge this space along the bundle length, thereby creating separate individual nanotubes (Strano et al., 2003). The "Cutting" theory postulates that microscopic domains of high temperature are produced by the collapse of cavitation bubbles during sonication, leading to localized sonochemistry that attacks the surface of CNTs, leaving an open hole in the tube side, before cutting them cleanly at the points of damage and separating the pieces from the other tubes in the bundles (Liu et al., 1998). However, the "Unzippering" theory, i.e., the debundling mechanism, cannot reasonably interpret the dispersion of SWCNTs in the SDBS solution, because the observed adsorption isotherms of SDBS on SWCNTs using shaking and sonication overlap with each other, but the dispersion of SWCNTs in SDBS solution was not observed in the case of shaking and was noticeably different from that of the case of sonication (Fig. 1). If the debundling mechanism captures the dispersion of SWCNTs in SDBS solution, the sorption of SDBS on the dispersed SWCNTs (i.e., after sonication) would be much higher than that on the undispersed SWCNTs (i.e., after shaking). This is because after debundling, a large fraction of the area of the bundled nanotubes that was previously inaccessible for the adsorption of SDBS would become accessible (Strano et al., 2003; Yang and Xing, 2010). Moreover, the stably suspended SWCNTs would exist in the SDBS solution as individual tubes owing to the debundling mechanism, rather than as the small aggregates observed in the TEM investigation (Fig. 4b). The "Cutting" theory also cannot explain the observed dispersion of SWCNTs in the SDBS solution because SWCNTs cannot be dispersed and stably suspended in water without SDBS (Fig. 1). From the TEM images (Fig. 4), we observed that the large aggregates of SWCNTs (Fig. 4a), composed of entangled smaller aggregates (Yang and Xing, 2007), are broken down into small aggregates (Fig. 4b) during the sonication process, as observed in previous studies (Lecoanet $e t$ al., 2004; Yudasaka et al., 2005). Moreover, after sonication, the separated smaller aggregates in the water coagulated quickly to re-form as large aggregates and precipitate because of the strong vdW forces between SWCNTs with smaller outer diameters (Lin and Xing, 2008; Lin et al., 2009); in SDBS solution, however, they remain in solution to form a stable suspension (Fig. 1). Therefore, we suggest that

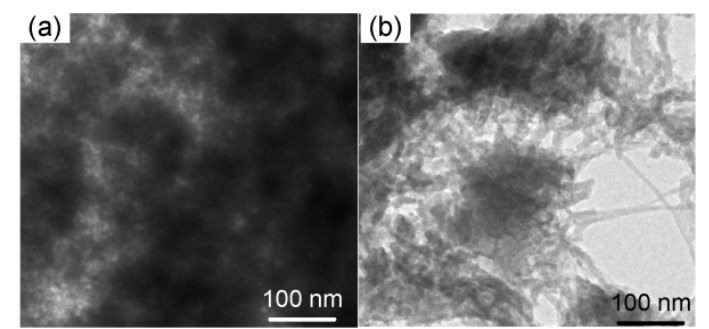

Fig. 4 TEM images of SWCNT aggregates before (a) and after (b) sonication 
a possible mechanism of suspension is that (1) the large aggregates of SWCNTs are broken down and separated into smaller ones by sonication and (2) the coagulation and aggregation of the smaller aggregates are inhibited by the steric/electrostatic repulsion between the SDBS molecules adsorbed on the SWCNTs, and thus, the small aggregates retain their stability in solution. The steric/electrostatic repulsion between the adsorbed SDBS molecules is demonstrated by the decrease in the zeta potential values with the increase in the amount of adsorbed SDBS (Fig. 5). This mechanism, in which the adsorbed surfactants induce electrostatic and/or steric repulsions to counterbalance the vdW attraction between nanotubes and thus maintain the stability of suspended CNTs, has also been suggested in previous studies (Lin and Xing, 2008; Lin et al., 2009; 2010). In contrast to SWCNTs, MWCNTs could be dispersed and stably suspended in NOM and tannic acid solutions by mild agitation such as shaking or magnetic stirring (Hyung et al., 2007; Hyung and Kim, 2008; Lin and Xing, 2008). The most plausible reason for this difference is that SWCNTs have smaller outer diameters and thus higher vdW attractions between tubes than MWCNTs (Lin and Xing, 2008; Lin et al., 2009), i.e., more energy is needed to break down and separate SWCNT aggregates. Therefore, MWCNTs with larger outer diameters $(20.9,27.8,42.7$, and $70.1 \mathrm{~nm})$, rather than those with smaller diameters $(9.4 \mathrm{~nm})$ and SWCNTs $(1.4 \mathrm{~nm})$, can be stably suspended in tannic acid solutions by shaking, resulting in the increase in the amount of suspended MWCNTs with the increase in the outer diameter (Lin and Xing, 2008).

\subsection{Stabilization of SDBS-suspended SWCNTs in the presence of cations}

Fig. 6 shows that SDBS-suspended SWCNTs in $2500 \mathrm{mg} / \mathrm{L}$ SDBS solution are destabilized and reaggregated by the addition of cations, exhibiting similarly shaped aggregation curves, i.e., the SDBSsuspended SWCNTs largely retain their stability at low ion concentrations up to a threshold value, and then they re-aggregate and are deposited suddenly when the ion strength exceeds the threshold value. As indicated by the increase in the zeta potential values of SDBS-suspended SWCNTs with the increase in the concentration of the cations (e.g., $\mathrm{Ca}^{2+}$, as a representative ion), as shown in Fig. 7 and suggested in our previous paper (Lin et al., 2009), the aggregation and deposition of SWCNTs above the threshold value can be attributed to the depression of the electric double layer by the added ions, which suppresses the electrostatic repulsion between suspended aggregates.

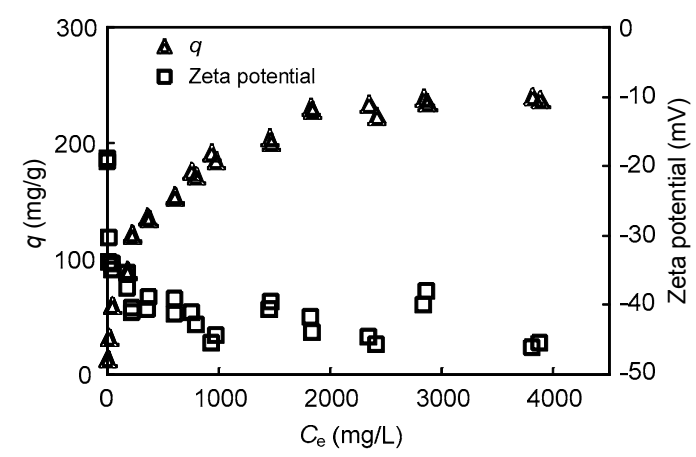

Fig. 5 Zeta potential values of SWCNT suspension in the SDBS solution at the SWCNT dose of $7500 \mathrm{mg} / \mathrm{L}$ and the amount of SDBS adsorbed on the SWCNTs versus the equilibrium SDBS concentration after sonication for $11 \mathrm{~h}$

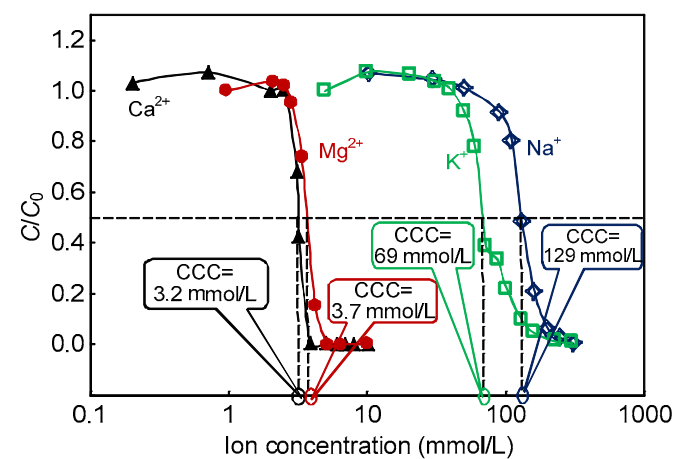

Fig. 6 SWCNT stabilization in $2500 \mathrm{mg} / \mathrm{L}$ SDBS solution as a function of ionic strength

$C / C_{0}$ : ratio of stably suspended SWCNT concentration in solution at a given ion concentration to the initial stably suspended SWCNT concentration

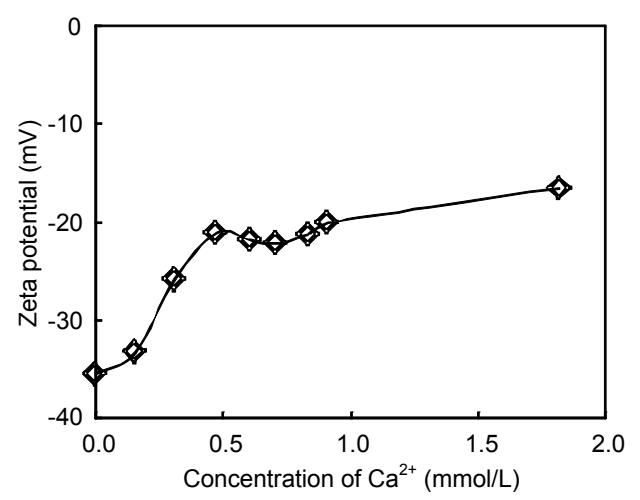

Fig. 7 Effect of $\mathrm{Ca}^{2+}$ concentration on the zeta potential values of an SWCNT suspension in $50 \mathrm{mg} / \mathrm{L}$ SDBS solution 
When the SWCNT surface charge is rapidly screened by the increasing ionic concentration, the electrostatic repulsion between them is completely suppressed, and hence, the energy barrier to aggregation is eliminated and every collision results in attachment of SWCNT sol (Lin and Xing, 2008; Lin et al., 2009). The CCC values of $\mathrm{Na}^{+}, \mathrm{K}^{+}, \mathrm{Ca}^{2+}$, and $\mathrm{Mg}^{2+}$ for reaggregation of suspended SWCNTs in $2500 \mathrm{mg} / \mathrm{L}$ SDBS solution were approximately $129,69,3.2$, and $3.7 \mathrm{mmol} / \mathrm{L}$, respectively (Fig. 6). The CCC values of divalent ions were an order of magnitude lower than those of monovalent ions, indicating that divalent ions are more effective counter-ions (Bouchard et al., 2012). All of the CCC values were much higher than the average concentrations of $\mathrm{Na}^{+}, \mathrm{K}^{+}, \mathrm{Ca}^{2+}$, and $\mathrm{Mg}^{2+}$ in fresh river water (i.e., 0.22, 0.034, 0.16, and $0.36 \mathrm{mmol} / \mathrm{kg}$, respectively) but lower than those in surface seawater (i.e., 470, 10.2, 53, and $10.3 \mathrm{mmol} / \mathrm{kg}$, respectively) (Broecker et al., 1982).

After the stable SWCNT suspension was diluted, the CCC values of the cations for re-aggregation of the suspended SWCNTs decreased significantly (Fig. 8a). Fig. 8a, for example, shows the effect of the $\mathrm{Ca}^{2+}$ concentration on the aggregation of stably suspended SWCNTs in a $2500 \mathrm{mg} / \mathrm{L}$ SDBS solution and the three diluted suspensions of SWCNTs with SDBS concentrations of 50,500 , and $1000 \mathrm{mg} / \mathrm{L}$. This decrease in the CCC values indicates that stably suspended SWCNTs do not retain environmental stability that would allow them to be transported long distances at significant concentrations, because, as soon as they are released into the environment, dilution will occur and environmentally relevant cations will coagulate and re-aggregate the diluted suspension of SWCNTs.

The concentrations of both SWCNTs and SDBS were reduced by the dilution of the SDBS-suspended SWCNTs. However, the decrease in the CCC values of the cations for the re-aggregation of suspended SWCNTs was a result of the decrease in the SDBS concentration rather than the decrease in the SWCNT concentration (Figs. 8b-8d). The CCC values of
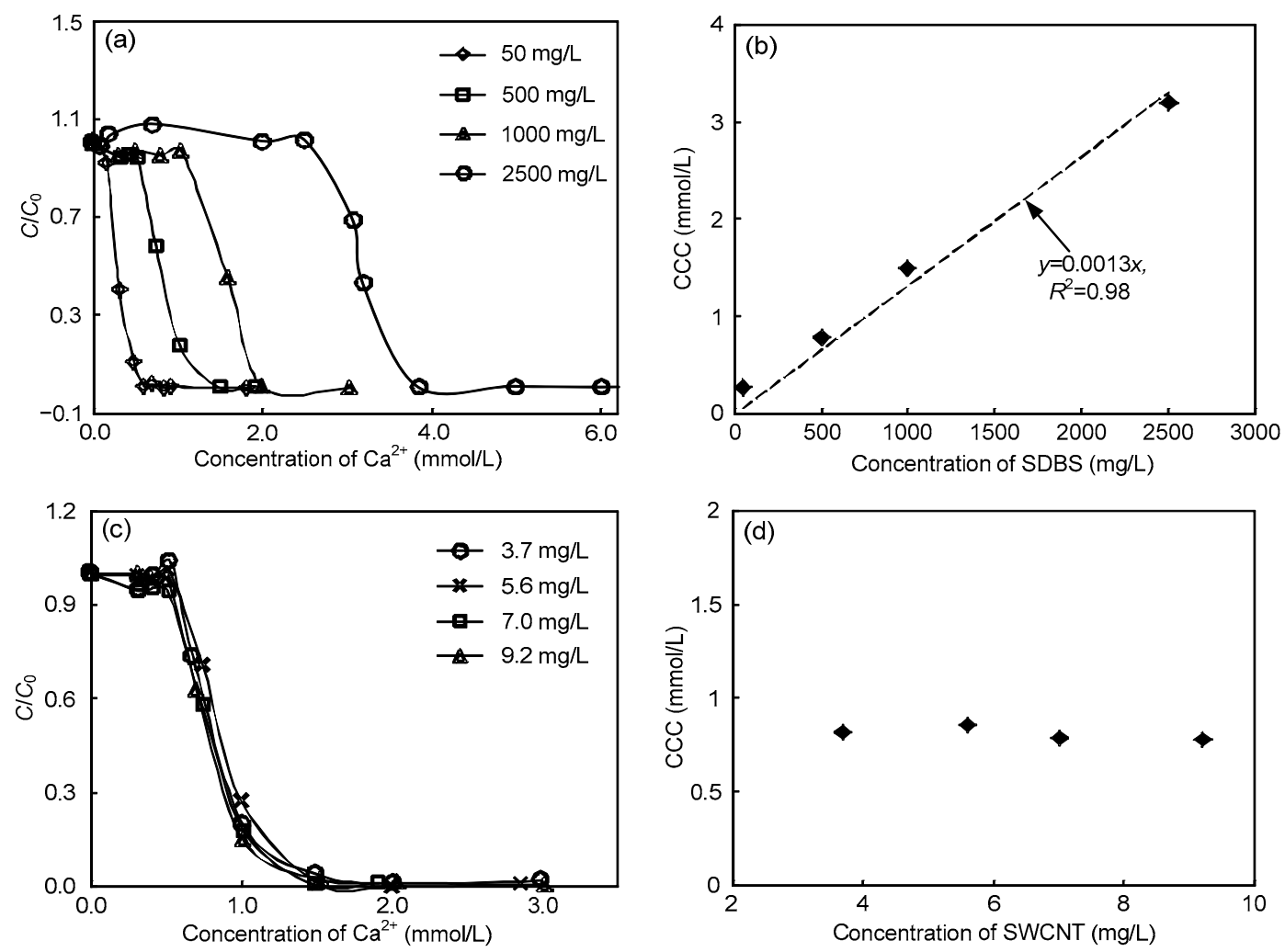

Fig. 8 Stability of SDBS-suspended SWCNTs at four SDBS concentrations (a) and at four SWCNT concentrations (c) as a function of ionic strength $\left(\mathrm{Ca}^{2+}\right)$, and the $\mathrm{CCC}$ values of $\mathrm{Ca}^{2+}$ for the aggregation of suspended SWCNTs as a function of SDBS (b) and SWCNT (d) concentrations 
SDBS-suspended SWCNTs were independent of the concentration of stably suspended SWCNTs (Figs. 8c and $8 \mathrm{~d}$ ). There was a linear relationship between the $\mathrm{CCC}$ values of $\mathrm{Ca}^{2+}$ ions and the SDBS concentrations in the suspension (Fig. 8b). Similar phenomena were observed by Bouchard et al. (2012) for the CCC values of $\mathrm{Na}^{+}$for re-aggregation of suspended MWCNTs and the SDS concentration in the suspension. Yang et al. (2013) also observed that the aggregate dimensions of stably suspended SWCNTs were not changed with the added SWCNT dose and SDBS concentrations, although a higher concentration of SWCNTs dispersed in the SDBS solution was observed when more SWCNTs or SDBS was added. Therefore, SWCNT dose and SDBS concentration cannot alter the CCC values of stably suspended SWCNTs because they cannot alter their aggregate dimensions. The CMC of SDBS was $963 \mathrm{mg} / \mathrm{L}$ (Yang et al., 2007). Molecular conformations of SDBS molecules above and below CMC will be significantly different as monomer at below CMC and micelle at above CMC (Yang et al., 2007). The linear relationship in the SDBS concentration ranging from 50 to $2500 \mathrm{mg} / \mathrm{L}$ (Fig. $8 \mathrm{~b}$ ) indicates that molecular conformations of SDBS molecules also cannot alter the CCC values of stably suspended SWCNTs. The observed dependence of the CCC values on the SDBS concentration could be attributed to (1) the steric/ electrostatic repulsion between the adsorbed SDBS molecules on the SWCNT surface, which is responsible for the retention of the stability of suspended SWCNTs in solution (Matarredona et al., 2003; Lin and Xing, 2008; Lin et al., 2009; 2010), and (2) the cationic suppression of the electrostatic repulsion by depressing the electric double layer to destabilize and re-aggregate the suspended SWCNTs (Lin and Xing, 2008; Lin et al., 2009).

\section{Conclusions}

We observed that bulk SWCNTs could not be dispersed and stably suspended in SDBS solution by shaking at $140 \mathrm{r} / \mathrm{min}$, although this can be achieved by sonication. Even SDBS-suspended SWCNTs do not retain their stability at environmental levels of relevant cations after dilution. These observations indicate that SWCNTs cannot be transported long distances at significant concentrations in the natural environment, thus posing potential ecological and environmental risks for the following reasons: (1) shaking at $140 \mathrm{r} / \mathrm{min}$ is a mild and typical agitation condition encountered in natural aqueous environments, whereas the agitation induced by sonication is not; and, (2) as soon as the suspensions are released into the environment, dilution occurs and environmentally relevant cations coagulate and re-aggregate the diluted suspension of SWCNTs. We also observed that the re-aggregation of suspended SWCNTs in the presence of the environmentally relevant cations was dependent on the SDBS concentration and not on the SWCNT concentration, with the CCC values of the $\mathrm{Ca}^{2+}$ for re-aggregation of SDBS-suspended SWCNTs decreasing with the decrease in the SDBS concentration in the diluted suspension. Both dispersion detergents and sonication play important roles in the dispersion of SWCNTs in water. The vigorous agitation by sonication breaks down the large aggregates of SWCNTs to smaller ones in the dispersion process, while the dispersion detergents (e.g., SDBS), especially the adsorbed fraction on the SWCNT surface, inhibit coagulation and aggregation through steric/electrostatic repulsion between the adsorbed SDBS molecules to maintain the stability of the suspension. This information is important for understanding the distribution and fate of SWCNTs in the environment and for estimating environmental exposure risks.

\section{References}

Bai, Y.C., Lin, D.H., Wu, F.C., et al., 2010. Adsorption of Triton X-series surfactants and its role in stabilizing multi-walled carbon nanotube suspensions. Chemosphere, 79(4):362-367. [doi:10.1016/j.chemosphere.2010.02.023]

Bouchard, D., Zhang, W., Powell, T., et al., 2012. Aggregation kinetics and transport of single-walled carbon nanotubes at low surfactant concentrations. Environmental Science \& Technology, 46(8):4458-4465. [doi:10.1021/es204 $618 \mathrm{v}]$

Broecker, W.S., Peng, T.H., Beng, Z., 1982. Tracers in the Sea. Eldigio Press, New York.

Cheng, J.P., Flahaut, E., Cheng, S.H., 2007. Effect of carbon nanotubes on developing zebrafish (Danio rerio) embryos. Environmental Toxicology and Chemistry, 26(4): 708-716. [doi:10.1897/06-272R.1]

Dunphy Guzmán, K.A., Taylor, M.R., Banfield, J.F., 2006. Environmental risks of nanotechnology: national nanotechnology initiative funding, 2000-2004. Environmental 
Science \& Technology, 40(5):1401-1407. [doi:10.1021/ es0515708]

Gottschalk, F., Nowack, B., 2011. The release of engineered nanomaterials to the environment. Journal of Environmental Monitoring, 13(5):1145-1155. [doi:10.1039/c0em 00547a]

Hyung, H., Kim, J.H., 2008. Natural organic matter (NOM) adsorption to multi-walled carbon nanotubes: effect of NOM characteristics and water quality parameters. Environmental Science \& Technology, 42(12):4416-4421. [doi:10.1021/es702916h]

Hyung, H., Fortner, J.D., Hughes, J.B., et al., 2007. Natural organic matter stabilizes carbon nanotubes in the aqueous phase. Environmental Science \& Technology, 41(1): 179-184. [doi:10.1021/es061817g]

Islam, M.F., Rojas, E., Bergey, D.M., et al., 2003. High weight fraction surfactant solubilization of single-wall carbon nanotubes in water. Nano Letters, 3(2):269-273. [doi:10. $1021 / \mathrm{n} 1025924 \mathrm{u}]$

Jia, G., Wang, H., Yan, L., et al., 2005. Cytotoxicity of carbon nanomaterials: single-wall nanotube, multi-wall nanotube, and fullerene. Environmental Science \& Technology, 39(5):1378-1383. [doi:10.1021/es0487291]

Lam, C.W., James, J.T., McCluskey, R., et al., 2004. Pulmonary toxicity of single-wall carbon nanotubes in mice 7 and 90 days after intratracheal instillation. Toxicological Sciences, 77(1):126-134. [doi:10.1093/toxsci/kfg243]

Lecoanet, H.F., Botterro, J.Y., Wiesner, M.R., 2004. Laboratory assessment of the mobility of nanomaterials in porous media. Environmental Science \& Technology, 38(19): 5164-5169. [doi:10.1021/es0352303]

Lin, D.H., Xing, B.S., 2008. Tannic acid adsorption and its role for stabilizing carbon nanotube suspensions. Environmental Science \& Technology, 42(16):5917-5923. [doi:10. 1021/es800329c]

Lin, D.H., Liu, N., Yang, K., et al., 2009. The effect of ionic strength and $\mathrm{pH}$ on the stability of tannic acid-facilitated carbon nanotube suspensions. Carbon, 47(12):2875-2882. [doi:10.1016/j.carbon.2009.06.036]

Lin, D.H., Liu, N., Yang, K., et al., 2010. Different stabilities of multiwalled carbon nanotubes in fresh surface water samples. Environmental Pollution, 158(5):1270-1274. [doi:10.1016/j.envpol.2010.01.020]

Liu, J., Rinzler, A.G., Dai, H.J., et al., 1998. Fullerene pipes. Science, 280(5367):1253-1256. [doi:10.1126/science.280. 5367.1253]

Matarredona, O., Rhoads, H., Li, Z., et al., 2003. Dispersion of single-walled carbon nanotubes in aqueous solutions of the anionic surfactant NaDDBS. The Journal of Physical Chemistry B, 107(48):13357-13367. [doi:10.1021/jp036 5099]

Matthijs, E., Holt, M.S., Kiewiet, A., et al., 1999. Environmental monitoring for linear alkylbenzene sulfonate, alcohol ethoxylate, alcohol ethoxy sulfate, alcohol sulfate, and soap. Environmental Toxicology and Chemistry,
18(11):2634-2644. [doi:10.1002/etc.5620181133]

McRae, S.G., 1988. Practical Pedology: Studying Soils in the Field. Ellis Horwood Ltd., Chichester.

Saleh, N.B., Pfefferle, L.D., Elimelech, M., 2008. Aggregation kinetics of multiwalled carbon nanotubes in aquatic systems: measurements and environmental implications. Environmental Science \& Technology, 42(21):7963-7969. [doi:10.1021/es801251c]

Saleh, N.B., Pfefferle, L.D., Elimelech, M., 2010. Influence of biomacromolecules and humic acid on the aggregation kinetics of single-walled carbon nanotubes. Environmental Science \& Technology, 44(7):2412-2418. [doi:10. 1021/es903059t]

Smith, B., Wepasnick, K., Schrote, K.E., et al., 2009. Influence of surface oxides on the colloidal stability of multi-walled carbon nanotubes: a structure-property relationship. Langmuir, 25(17):9767-9776. [doi:10.1021/la901128k]

Strano, M.S., Moore, V.C., Miller, M.K., et al., 2003. The role of surfactant adsorption during ultrasonication in the dispersion of single-walled carbon nanotubes. Journal of Nanoscience and Nanotechnology, 3(1):81-86. [doi:10. 1166/jnn.2003.194]

Yang, K., Xing, B.S., 2007. Desorption of polycyclic aromatic hydrocarbons from carbon nanomaterials in water. Environmental Pollution, 145(2):529-537. [doi:10.1016/j. envpol.2006.04.020]

Yang, K., Xing, B.S., 2010. Adsorption of organic compounds by carbon nanomaterials in aqueous phase: Polanyi theory and its application. Chemical Reviews, 110(10):59896008. [doi:10.1021/cr100059s]

Yang, K., Zhu, L.Z., Xing, B.S., 2006. Adsorption of polycyclic aromatic hydrocarbons by carbon nanomaterials. Environmental Science \& Technology, 40(6):1855-1861. [doi:10.1021/es052208w]

Yang, K., Zhu, L.Z., Xing, B.S., 2007. Sorption of sodium dodecylbenzene sulfonate by montmorillonite. Environmental Pollution, 145(2):571-576. [doi:10.1016/j.envpol. 2006.04. 024]

Yang, K., Yi, Z.L., Jing, Q.F., et al., 2013. Sonication assisted dispersion of carbon nanotubes in the aqueous solution of the anionic surfactant SDBS: the role of sonication energy. Chinese Science Bulletin, 58(17):2082-2092. [doi:10. 1007/s11434-013-5697-2]

Yudasaka, M., Fan, J., Miyawaki, J., et al., 2005. Studies on the adsorption of organic materials inside thick carbon nanotubes. The Journal of Physical Chemistry B, 109(18): 8909-8913. [doi:10.1021/jp050980f]

Zajic, J.E., Seffens, W., Panchal, C., 1983. Biosurfactants. Critical Reviews in Biotechnology, 1(2):87-107. [doi:10. 3109/07388558309082580]

Zhang, X.T., Zhang, J., Wang, R.M., et al., 2004. Cationic surfactant directed polyaniline/CNT nanocables: synthesis, characterization, and enhanced electrical properties. Carbon, 42(8-9):1455-1461. [doi:10.1016/j.carbon.2004. 01.003] 


\section{中文概要:}

本文题目: 单壁碳纳米管在阴离子表面活性剂溶液中的分散悬浮和团聚沉降性能研究

Dispersion and aggregation of single-walled carbon nanotubes in aqueous solutions of anionic surfactants

研究目的: 纳米颗粒在水中的悬浮和团聚性能是决定它们在环境中迁移行为及潜在健康和环境风险 影响范围的关键。表面活性剂不仅在环境中普遍存在, 而且是工业制备纳米颗粒稳定悬 浮液的主要分散剂。本文以单壁纳米碳管为代表, 研究震荡扰动及稀释等模拟环境条件 下其在阴离子表面活性剂溶液中的分散悬浮和团聚沉降性能, 为评价纳米颗粒排放进入 环境后的潜在风险提供依据。

创新要点: 现有研究认为, 纳米颗粒由于能在水中稳定悬浮, 其排放到环境中会产生长距离迁移并 存在造成大范围污染的可能性和生态健康风险。在本文中, 震荡扰动及稀释等模拟环境 条件的研究表明, 单壁碳纳米管在环境中长距离迁移并造成大范围污染的可能性和风险 较小。

研究方法: 通过比较震荡扰动 (模拟环境条件) 和超声辅助两种分散悬浮方式及有无添加十二烷基 苯磺酸钠（SDBS）阴离子表面活性剂条件下的单壁碳纳米管在水中的悬浮性能（图 1), 研究单壁碳纳米管能否在环境中被分散悬浮。通过研究 $\mathrm{Na}^{+}, \mathrm{K}^{+}, \mathrm{Ca}^{2+}$ 和 $\mathrm{Mg}^{2+}$ 等环境主 要阳离子存在时 SDBS 稳定悬浮的单壁碳纳米管悬浮性能及与 SDBS 浓度等的相关性 （图 6 和 8 ）, 探明稳定悬浮的单壁碳纳米管能否在环境稀释过程中和环境阳离子存在下 保持稳定悬浮。

重要结论: 在超声辅助下, 单壁碳纳米管可以在 SDBS 阴离子表面活性剂溶液中稳定分散悬浮, 但 不能在水中稳定分散悬浮。在无超声辅助、仅通过机械震荡的情况下, 单壁碳纳米管无 法在水中和 SDBS 溶液中稳定分散悬浮。对于已经在 SDBS 溶液中稳定悬浮的单壁碳纳 米管, 它们在 $\mathrm{Na}^{+}, \mathrm{K}^{+}, \mathrm{Ca}^{2+}$ 和 $\mathrm{Mg}^{2+}$ 等环境主要阳离子存在时也会脱稳形成团聚沉降, 且该团聚沉降行为取决于悬浮溶液中 SDBS 的浓度。当 SDBS 稳定悬浮的单壁碳纳米管 在环境中被稀释时, SDBS 浓度被稀释降低, 会迅速导致单壁碳纳米管团聚沉降。因此, 单壁碳纳米管很难在环境中被分散悬浮, 即使是已经稳定分散悬浮的单壁碳纳米管, 也 会在环境稀释和环境阳离子的作用下快速团聚沉降。由此可见, 单壁碳纳米管在环境中 长距离迁移并造成大范围污染的可能性和风险较小。

关键词组: 分散悬浮; 团聚沉降; 单壁碳纳米管; 阴离子表面活性剂; 超声 